\title{
A Peer Group Mentoring Model: Implementation at a Greek Secondary School Unit
}

\author{
Venetia Kapachtsi, Ph.D. \\ Postdoctoral Researcher \\ University of Macedonia \\ 156 Egnatia str., Thessaloniki 54636 \\ Ioanna Papavasiliou-Alexiou \\ Assistant Professor \\ University of Macedonia \\ 156 Egnatia str., Thessaloniki 54636
}

\begin{abstract}
In this study, we developed and implemented a peer group mentoring model (PGM)by focusing on recent theories of teachers' learning and mentoring and the research data of a case study, a junior high school of Eastern Thessaloniki in Greece. The research took place from October 2016 to May 2017, with six teachers as mentees and the researcher in the role of the mentor. The goal of the implementation of the mentoring model was the participants' involvement in the mentoring relationship through the development of effective strategies, such as peer observation, collaborative culture and reflective process under mentor's guidance.
\end{abstract}

Keywords: Mentoring, reflection, observation, support, action research

\section{Introduction}

Mentoring is widely supported in many educational systems; moreover, guidance of newly appointed teachers provided by experts for a certain period of time is considered both essential and a prerequisite for their permanent appointment (Bullough, 2005; Bullough, Young, Hall, Draper \& Smith, 2008; Laskarakis \& Papavasiliou Alexiou, 2013). In order to enhance teaching effectiveness and professional growth, ongoing guidance is provided by mentors in countries around the world, even to appointed teachers (Orland-Barak, 2010; Stanulis, Little \&Wibbens2012; Geeraerts, Tynjala, Heikkinen, Pennanen \& Gijbels, 2015; Wang \& Odell, 2007).

A mentor, taking on supervisory, advisory and even evaluative role is defined as a teacher with a wide educational and teaching experience (Aspfors \& Fransson, 2015;2013; Richter, Kunter, Lüdtke, Klusmann, Anders \& Baumert, 2013; Strong \& Baron, 2004); mentoring is described as a complex interactive process between two persons(mentor-mentee), with different levels of experience and knowledge. The current literature review reports that supporting the mentee both instructionally and psychologically/psychosocially is the mentor's primary purpose (Gold, 1996; Richteret al., 2013).

Mentoring models developed over the past two decades, on the one hand point out a variety of relationships between mentors and mentees and on the other hand focus on the various ways mentees could develop professionally (diagram1).

The current literature review mentions a distinction between the bureaucratic managerial and the participatory model (Harrison, Dymoke \& Pell, 2006), and also between conventional and educational mentoring models (Feiman-Nemser, 2001). Additionally, the knowledge transmission and the knowledge transformation models are proposed by some researchers (Cochran-Smith \& Paris, 1995; Wang \& Odell,2007).

The managerial, conventional and transformational models are based on the behaviorism, which perceives learning as an accumulation of knowledge provided by experts. In this respect, learning is perceived as a one-way process in which "learners are passive recipients of information" and mentors obtain the role of the expert, who transmit their knowledge within a hierarchically structured relationship (Richter et al., 2013, p.168). In this kind of learning environment, the novice adapts to the mainstream culture of the school. 
Diagram 1: Mentoring Models

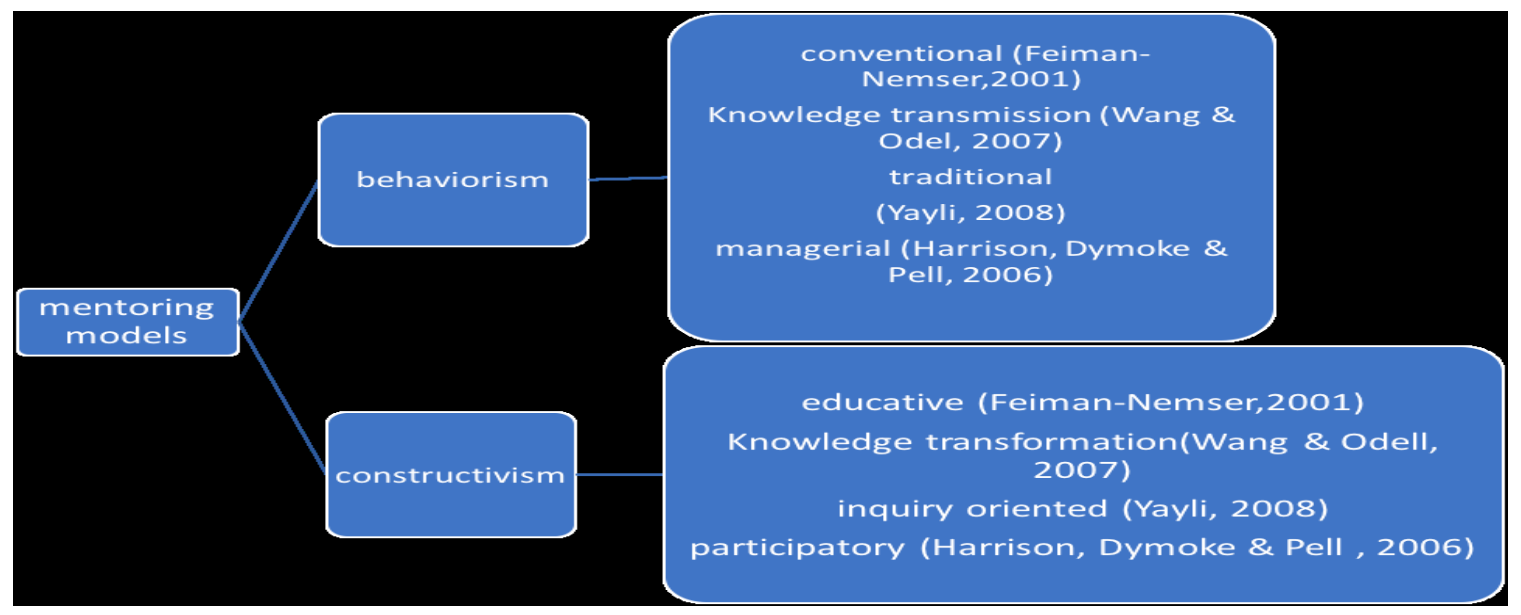

The participatory, educational and knowledge transformation models are based on constructivism theory, according to which mentor leads mentees to discover new knowledge and theory based on their own previous knowledge. Thus, a cooperative kind of relationship emerges between mentor and mentee; as a result, this approach facilitates exchange and generation of ideas and also supports implementation of change and innovation in class (Casale, 2011; Crasborn, Hennissen, Brouwer, Korthagen \& Bergen, 2011; Ginkel, Verloop \& Denessen, 2016; Langelotz, 2013;Luo, 2013; Thousand, Villa \&Nevin, 2006). In other words, under the mentor's guidance teachers can develop by participating actively, collaboratively, and reflectively; thus, mentoring becomes the "new mantra for education" (Sundli, 2007,p.201).

The contexts within which mentoring is provided depend on the professional needs of the participants. More specifically: a) a novice teacher could be guided by an expert (Bullough, 2005; Bullough et al., 2008; Devos, 2010; Orland-Barak, 2010), b) a group of novice teachers could receive guidance from an expert (Pennanen, Tynjala, Heikkenen, Pennanen \& Gijbels, 2014) and c) a mixed group of both novice and experienced teachers could receive guidance from an expert (Peer-Group Mentoring) (Geeraerts et al., 2015). In Finland, the PeerGroup Mentoring (PGM) model developed gradually from 2010 to 2016 aiming at both novice and experienced teachers' professional development and job satisfaction (Geeraerts et al., 2015; Pennanen, Geeraerts, Tynjala \& Markkanen, 2014).

Key elements of the PGM model, the one we have followed in our research, are considered a) teamwork, b) exchange of experience within the team, c) autonomy and development of the school unit, e) disconnection of the mentor to any kind of evaluation and f) combination of theoretical and practical knowledge. Apart from the context, the relationship which evolves between mentor and mentee while implementing mentoring should seriously be taken into consideration. It is described throughout the literature as a dynamic relationship, developed at different stages, from beginning to end (Kram, 1983; Veenman \& Denessen, 2001).

In particular, Kram (1983), who conducted a thorough study on mentoring, mentions four evolutionary stages. In the first stage, called "Initiation", mentor and mentee are appointed; in the second one, referred to as "Cultivation" of the relationship, the two members are aware of each other and start to co-decide the purpose of their cooperation and their roles. During this stage, the mentee receives necessary support professionally and psychosocially. In the third stage, that is the "Separation", guidance comes to a completion and therefore, the mentee, who has obtained experience and appropriate knowledge, can cope with his / her duties without supervision and guidance. Finally, in the fourth stage of guidance, that is the "Redefinition", the two members are to re-define their relationship and co-decide the frequency and the conditions of possible future contact and interaction.

\section{The Mentoring Model: Description}

In our research, we developed and implemented a peer group mentoring model (PGM) at a secondary school unit. The six participants, in the role of the mentees, who covered a wide range both in terms of age and experience, from novice to experienced teachers, were specialized in different subjects (Greek language, foreign languages and math), while the researcher in the role of the mentor was regarded as an expert teacher, appointed at this school unit. 
Taking into consideration the participants' needs and the current literature review, we developed the mentoring model, in four stages, described below (diagram 2).

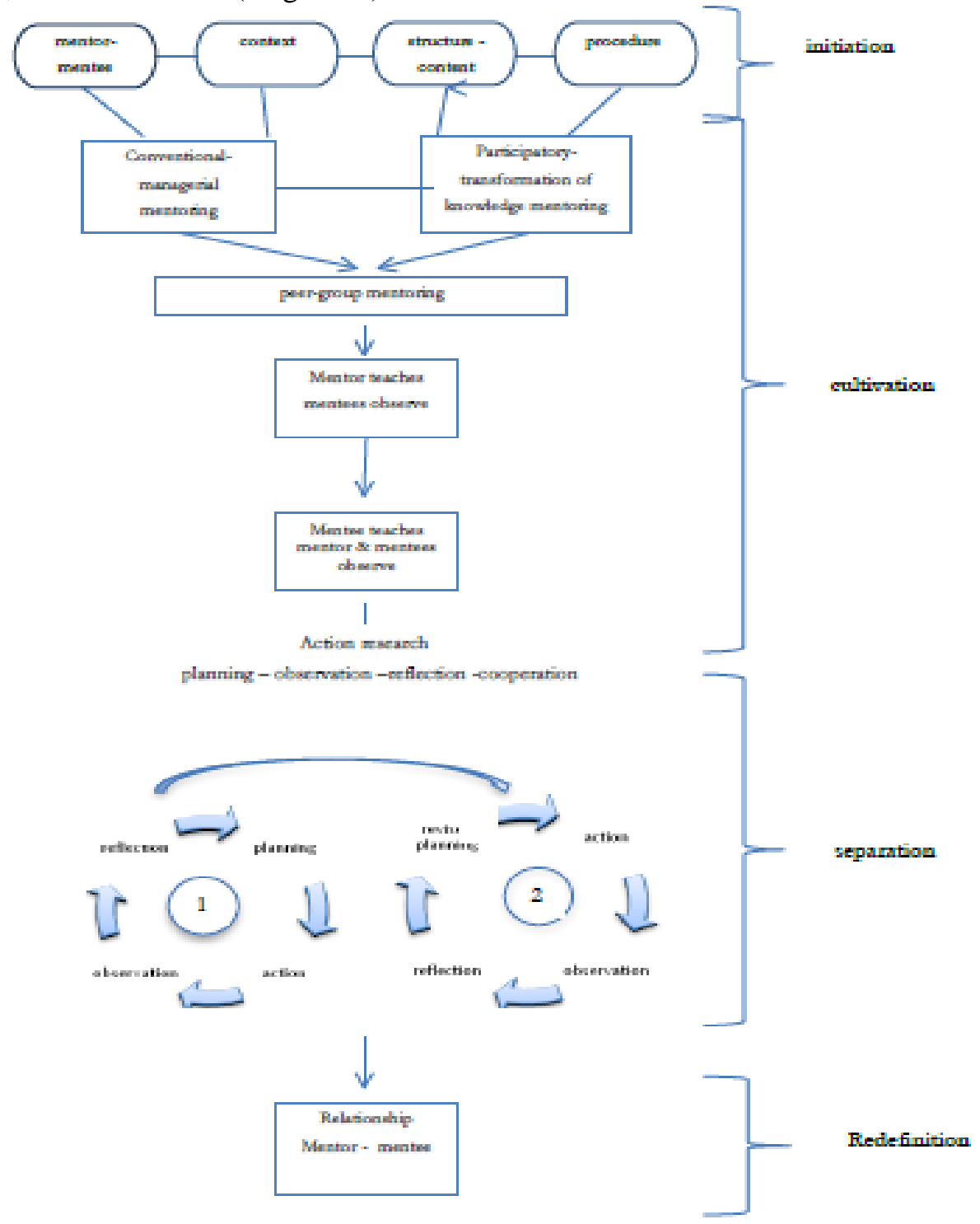

1. "The Initiation": More specifically, at the first stage, we concentrated on four basic principles (Makland, 2008; Richter et al., 2013):

a) mentor's choice;

b) the context where mentor - mentee relationship develops;

c) the structure and content of the mentoring model;

d) the process itself.

As far as the choice of the mentor is concerned, the author (1), as an experienced teacher and a researcher had the knowledge and skills to conduct an effective professional development process for teachers, introducing new teaching practices, initiating reflection and practicing communication skills (Langelotz, 2013; Luo, 2013; Villa, Thousand \& Nevin, 2004).

Mentoring took place within the school unit, as it is the place where collaboration with the colleagues and peer observation in classrooms could be initiated (MacGilchricst, Myers \& Reed 2004).

Regarding the content and the structure of the mentoring model which we developed, these were determined by the participants' needs; thus, initially, we identified teachers' professional needs, after having analyzed the questionnaires, distributed to them and then we concentrated on the renewal of their teaching practices according to the results. 
Specifically, we focused on the implementation of collaborative method of teaching, deepening their knowledge in their profession, and mobilizing students 'interest (Casale, 2011; Kapachtsi \& Kakana, 2014; Villa, Thousand, $\&$ Nevin, 2004).Finally, the process, which the six participants were involved throughout the mentoring model implementation, was the action research (Hannover Research, 2014;Kapachtsi, \& Kakana, 2014; Langelotz, 2013), as it is considered an appropriate method for teachers' professional development; moreover, action research was supported by the mentor and was implemented with participants' collaboration and interaction at a voluntary base; thus, the participants got involved in peer observation, developed reflective processes and initiated new collaborative teaching practices for a whole school year (Kapachtsi \& Kakana, 2015; Lancelot, 2013; Luo, 2013; Villa, Thousand \& Nevin, 2004). The main features of the action research, which the participants were involved in, are depicted in (table 1).

Table 1: The Basic Points of Action Research

\begin{tabular}{|l|l|}
\hline Purpose & Teachers' Professional development \\
\hline Starting point & $\begin{array}{l}\text { Explore needs } \\
\text {-/ Identifying an actual problem }\end{array}$ \\
\hline Developing practices & From a qualified researcher \\
\hline Steps & Planning-acting-observing reflecting \\
\hline Development framework & school unit \\
\hline Direction & Bottom - up \\
\hline $\begin{array}{l}\text { Key concepts of } \\
\text { action research }\end{array}$ & $\begin{array}{l}\text { Reflection, peer observation, } \\
\text { cooperation }\end{array}$ \\
\hline
\end{tabular}

Teachers' participation in the process was the researcher's initial aim; during a school meeting at the beginning of the school year, all teachers were informed about the mentoring model implementation and finally, six of them declared willing to participate. The first meeting of the mentor-mentees aimed to discuss the results of the questionnaires concerning the mentees' professional needs, their aspirations and expectations from the specific research effort. Another issue discussed was the agenda of the group meetings, as the participants would be expected to meet either after finishing their school duties or at their colleagues' classrooms for peer observation; thus, with mentor's support, modifications of the timetable were made to avoid school function disturbance.

Key concepts of action research, such as reflection and peer observation we reanalyzed during the following two meetings; moreover, the researcher tried to be accurate and extra informative, as teachers were not used in getting involved in these two basic procedures. It had become obvious to the participants that during peer observation, teachers were able to co-investigate educational issues through continuous feedback; the observers could focus on certain subjects, such as the organization of the module, students' reaction during the teaching process and the climate created in classroom. In the next meeting, other important issues such as the theoretical framework of the collaborative teaching method, development of the pedagogical framework, reorganization of space, distribution of students in heterogeneous groups, allocation of roles and responsibilities within the groups were presented and discussed by the mentor.

2. "Cultivation stage": Moving to the second stage of the mentoring model, its actual implementation became more apparent, while the mentees started receiving the necessary support and guidance at a professional and psychosocial level. Based on the current literature, we combined the technocratic with the participatory mentoring model, considering that the participants, on the one hand should obtain knowledge upon collaborative teaching, on the other hand should develop professionally and be transformed into contemplated reflective thinkers; thus, for the above sake, the mentor taught her students, applying new collaborative techniques. More specifically, the collaborative teaching approach in English subject was demonstrated by the mentor inher classroom, within a period of two months, while the six teachers seated at the row places of the classroom, observed the mentor, keeping notes at the observation sheets, distributed by the mentor. After each observation, a meeting was arranged and trickyor tangible points of the mentor's teaching were discussed and clarified within the group. The mentor's teaching was followed by the participants' individual teaching. The mentor with the rest of the mentees observed their colleague, keeping notes upon on his/her teaching; afterwards, feedback, concerning teaching was given both by the mentor and the mentees. It's noteworthy the fact, that although the participants were specialized in different subjects, they could observe their colleagues' modules without any difficulty, providing ideas. 
3. "Separation stage": At the third stage of the implementation of the mentoring model, the participants continued observing their colleagues, getting more and more involved in reflective processes effectively, applying new teaching techniques; they experienced an ongoing planning-acting-observing-reflecting procedure with parallel feedback and support, given both by the mentor and the mentees.

There was a constant critical view of the new ideas, knowledge and skills that were being developed. Further meetings, either individually or within the group were held with the mentor, discussing the positive points and the problems that arose in classrooms; as a result, a better understanding of the educational reality was achieved which facilitated the implementation of new practices, adapting them to the different learning environments, as it became clear that nothing is achieved with ready-made recipes. The participants cultivated the skill to identify the difficulty, to plan, to invent a new alternative solution and observe the outcome of the implementation. Gradually, it became evident that the participants gained independence and confidence in their abilities.

At this point guidance was completed and the mentees had obtained the experience and the appropriate knowledge to cope with their duties. The uninterrupted presence of all in our meetings, their zeal and the continuous effort revealed teachers' need for support, cooperation, communication, exchange of ideas, knowledge and experience. It was obvious that teaching became more and more attractive and the cooperation in our team gave them support to continue.

4. "Redefinition stage": Almost at the end of the school year, we reached the stage of "Redefinition"; thus, the relationship had to be redefined. In particular, it was discussed whether and under what conditions the mentor's and the participants' contact and interaction would continue the following year. At the last meeting, the group decided that for the next school year they could cooperate with peer observations and discussions on problemsolving, under mentor's support. As the researcher-mentor is appointed in the school unit; the cooperation within the group is considered achievable for further time.

\section{Conclusion}

The peer group mentoring model developed in our study combines the technocratic and participatory mentoring models, concentrating particularly on the principles of the constructivism, transforming mentees into active learners; thus, the implementation of the model was faced as a dynamic process, since the mentees' personal and professional abilities were mobilized. Focusing on the participants' professional needs and on the actual teaching in classroom, a new perspective with a direct and specialized training within the workplace was provided. The mentor, an expert teacher coming from the same school unit, provided continuous feedback and support to mentees, by involving them in teaching, observation, feedback and reflection; as a result, the participants adopted innovations and changed attitudes. The development of reflection, discussions and peer observations under the mentor's guidance emerged as an important asset for implementing practices and developing collaboration and communication. The important contribution of action research emerged throughout the implementation of the mentoring model, as the mentees were actively involved, making the continuous change of teaching-learningcooperation an integral part of their daily school life.

At a professional level, the participants experimented, addressed the strengths and weaknesses, explored the limits and possibilities of implementing new practices and shared the difficulties encountered in the teaching practice.

\section{References}

Aspfors, J. \& Fransson., G. (2015.) Research on mentor education for mentors ofnewly qualified teachers: A qualitative meta-synthesis. Teaching and Teacher Education, 48, 75-86.

Bullough, R.V. (2005). Being and becoming a mentor: school-based teacher educatorsand teacher educator identity. Teaching and Teacher Education, 21, (2), 143-155.

Bullough, R.V., Young, J. R., Hall, K. M., Draper, R. J. \& Smith, L. K. (2008).Cognitive complexity, the first year of teaching, and mentoring. Teaching and Teacher Education, 24, (7), 1846-1858.

Casale, M.A (2011). Teachers' perceptions of professional development: An exploration of delivery models. (Unpublished doctorate dissertation). Johnson and Wales University, North Miami, FL. Retrieved from http://www.eric.ed.gov

Cochran-Smith, M., \& Paris, C. L. (1995). Mentor and mentoring: did Homer have it right. In J. Smyth (Ed), Critical discourses on teacher development. London: Cassell. 
Crasborn, F., Hennissen, P., Brouwer, N., Korthagen, F. \& Bergen, T. (2011).Exploring a two-dimensional model of mentor teacher roles in mentoring dialogues. Teaching and Teacher Education, 27, (2), 320-331.

Devos, A. (2010). New teachers, mentoring and the discursive formation ofprofessional identity. Teaching and Teacher Education, 26, (5), 1219-1223.

Geeraerts, K., Tynjala, P., Heikkenen, L.T.H., Pennanen, M. \&Gijbels, D. (2015).Peer-group mentoring as a tool for teacher development. European Journal of Teacher Education, 38, (3), 358-37.

Ginkel, G., Verloop, N. \&Denessen, E. (2016). Why mentor? Linking mentor teachers' motivations to their mentoring conception. Teachers and Teaching:theory and practice, 22, (1), 101-116.

Gold, Y. (1996). Beginning Teacher support: attrition, mentoring and induction. In J.Sikula (Ed), Handbook of research on teacher education (2nd ed., pp. 548-616).N.Y: Macmillan.

Hanover Research (2014). Faculty Mentoring Models and Effective Practices. Academy Administration Practice. Retrieved fromhtpp://www.hanoverreasearch.com.

Harrison, J., Dymoke, S. \& Pell, T. (2006). Mentoring beginning teachers insecondary schools: an analysis of practice. Teaching and Teacher Education, 22,(8), 1055-1067.

Kapachtsi, V. \& Kakana, D. M. (2014) Traditional classrooms transformed intomodern school environments through collaborative action research. International Journal of Elementary Education, 3, (3), 58-64.

Kapachtsi, V. \& Kakana, D-M. (2015). Could the principal help teachers' professional development within the school unit? Introduction to the 3rd International Symposium, Modern Dimensions in Teacher Education, Volos.

Kram, K. (1983). Phases of the Mentor Relationship. The Academy of Management Journal, 26, (4), 608-625.

Langelotz, L. (2013). Teachers' peer group mentoring - Nine steps to heaven? Education Inquiry, 4, (2), 375-394.

Laskarakis, G., \&Papavassiliou-Alexiou, I. (2013). The Institution of Mentoring andits Contribution to Teachers' Professional Development. [O $\theta \varepsilon \sigma \mu o ́ \varsigma ~ \tau o v ~ M \varepsilon ́ v \tau o \rho \alpha \kappa \alpha \imath ~ \eta ~ \sigma u \mu ß o \lambda \eta ́ ~ \tau o v ~ \sigma \tau \eta v ~ \varepsilon \pi \alpha \gamma \gamma \varepsilon \lambda \mu \alpha \tau 1 \kappa \eta ́ ~ \alpha v \alpha ́ \pi \tau v \xi \eta$ $\tau \omega v \varepsilon \kappa \pi \alpha 1 \delta \varepsilon v \tau \iota \kappa \omega ́ v]$. ELESYP Scientific Journal, 101, 284-295. Athens: Hellenic Society of Counseling andGuidance.

Luo, W-H. (2013) An exploration of professional development programs for teachersof collaborative teaching of EFL in Taiwan: A case study. Asian Pacific Education, 23, (3), 403-412.

MacGilchricst, B., Myers, K. \& Reed., J. (2004). The intelligent school. Sage Publications.

Makland, A. (2008). In- service teacher training program. A comparative studybetween Egypt and Japan. Journal of International Educational Cooperation 3,107-112.

Orland-Barak, L. (2010). Learning to Mentor-as-Praxis: Foundations for a curriculum in teacher Education. NY: Springer.

Pennanen, M., Geeraerts, K., Tynjala, P. \& Markkanen, I. (2014). The Finnish Peer-Group Mentoring Model. Finnish Institute for Educational Research, University of Jyväskylä, Finland. Retrieved from http://www.osaavaverme.fi/en/dissemination.

Richter, D., Kunter, M., Lódtke, O., Klusmann, U., Anders, Y. \& Baumert, J. (2013).How different mentoring approaches affect beginning teachers' development inthe first years of practice. Teaching and Teacher Education, 36, (1),166-177.

Stanulis, R.N., Little. S. \& Wibbens, E. (2012). Intensive mentoring that contributesto change in beginning elementary teachers' learning to lead classroom discussions.Teaching and Teacher Education, 28, (1), 3243.

Strong, M. \& Baron, W. (2004). An analysis of mentoring conversations with beginning teachers: suggestions and responses. Teaching and Teacher Education, 20,(1), 47-57.

Sundli, I. (2007). Mentoring- A new mantra for education? Teaching and Teacher Education, 23, (2), 201-214.

Thousand J, Villa, R. \&Nevin, A. (2006) The many faces of collaborative planning and teaching. Theory into Practice, 45, (3), 239-247.

Veenman, S., \&Denessen, E. (2001): The coaching of teachers. Results of five training studies, Educational Research and Evaluation, 7 (4), 385-417.

Villa, R., Thousand, J. \&Nevin, A. (2004). A guide to co-teaching: Practical tips forfacilitating student learning. Thousand Oaks, CA: Corwin Press.

Wang, J. \& Odell, S. J. (2007). An alternative conception of mentor-novice relationships: learning to teacher in reform-minded ways as a context. Teaching and Teacher Education, 23, (4), 473-489. 